\title{
- Ecletismo do Paradigma da Sustentabilidade: construção e análise a partir dos estudos organizacionais
}

\author{
Luciano Munck ${ }^{1}$ \\ Rafael Borim de Souza ${ }^{2}$
}

\section{Resumo}

Este artigo possui dois objetivos principais: (1) investigar as nuanças que um paradigma da sustentabilidade, como proposição de lente de observação da realidade para os contextos organizacionais deve assumir; e (2) apresentar e definir um paradigma da sustentabilidade, eclético, dialógico e flexível, por meio do qual o desenvolvimento sustentável possa ser assumido como um fenômeno de pesquisa coerente junto aos estudos organizacionais. Realizou-se um estudo qualitativo, exploratório e bibliográfico. Foi desenvolvido um referencial teórico com o intuito de observar possíveis inter-relações entre algumas discussões sobre o desenvolvimento sustentável e contribuições específicas extraídas dos estudos organizacionais. O paradigma da sustentabilidade, em suma, é concebido pelo estudo da relação entre o desenvolvimento sustentável e os estudos organizacionais, uma vez que compreende o desenvolvimento sustentável como um fenômeno de investigação que importa ao contexto das organizações.

Palavras-chave: Desenvolvimento Sustentável. Estudos Organizacionais. Paradigma.

\section{Introdução}

Conceder um lócus paradigmático aos fenômenos de pesquisa relacionados aos estudos organizacionais torna-se, cada vez mais, um exercício analítico que ganha níveis de complexidade que reforçam a capacidade limitada

\footnotetext{
${ }^{1}$ Vice-Coordenador do Programa de Pós-Graduação em Administração da Universidade Estadual de Londrina (PPGA-UEL). Doutor em Administração pela Faculdade de Economia, Administração e Contabilidade da Universidade de São Paulo (FEA-USP). End.: Rodovia Celso Garcia Cid - Pr 445 Km 380 - Campus Universitário, Londrina-PR. Cx. Postal 6001. CEP: 86051-980 - Brasil. E-mail: munck@uel.br.

${ }^{2}$ Doutorando em Administração pelo Programa de Pós-Graduação da Universidade Federal do Paraná (PPGADM-UFPR) e Mestre em Administração pelo Programa de Pós-Graduação em Administração da Universidade Estadual de Maringá em consórcio com a Universidade Estadual de Londrina (PPA-UEM/UEL). End.: Rua Senador Souza Naves, 2677, apto.1601, Londrina - PR. CEP: $86015-430$ - Brasil. E-mail: rafaborim@yahoo.com.

Artigo recebido em: 09/06/2010. Aceito em: 14/02/2011. Membro do Corpo Editorial Científico responsável pelo processo editorial: Emerson Antonio Maccari.
}

Esta obra está sob a Licença Creative Commons Atribuição-Uso. 
da racionalidade humana. Ao se identificar com uma determinada escola do conhecimento ou ao defender os preceitos que regem uma abordagem epistemológica específica, inconscientemente, por vezes conscientemente, o pesquisador assume uma identidade que despreza uma quantidade considerável de contribuições científicas, as quais poderiam incrementar as informações coletadas em quantidade e qualidade, e, principalmente, conceder melhor qualificação às categorias de análise a serem pesquisadas (LICOLN; GUBA, 2006).

No que se refere ao tratamento do desenvolvimento sustentável por diretrizes estabelecidas em algumas ramificações dos estudos organizacionais que buscam pesquisar tal expressão, é possível identificar dois parâmetros discursivos marcadamente distantes: (1) o primeiro foca a operacionalização de indicadores e mensurações que comprovem, quantitativamente, a existência de comportamentos organizacionais orientados para o desenvolvimento sustentável; e (2) a segunda busca fundamentar uma discussão teórica que desqualifique os trabalhos empíricos desenvolvidos na primeira vertente, ao qualificá-los como reducionistas e simplistas (MEBRATU, 1998; MILNE; KEARINS; WALTON, 2006).

Esses dois movimentos extremistas não dialogam entre si, logo, não trocam conhecimentos e, por consequência desse distanciamento, ficam isolados em suas convenções paradigmáticas, as quais são assumidas e aceitas por aqueles que as defendem como verdades absolutas e inquestionáveis. A incompatibilidade entre essas posições radicais não é exclusiva à discussão do desenvolvimento sustentável e não é de propriedade única dos fenômenos estudados pela Administração, mas sim, conforme admoestações de Mattos (2009), é inerente à proposição de relacionar quaisquer fenômenos que quando analisados separadamente produzem inúmeras dissenções.

Kuhn (1970) em suas discussões já previa que toda análise sobre temas em desenvolvimento exigiria a evolução de padrões de pensamentos cristalizados pelo tempo, os quais, pela devoção de seus seguidores, continuariam sendo gradativamente perpetuados e protegidos, mesmo que por meio de comprovadas manifestações da realidade fique denunciada a incongruência de suas contribuições para com aquele momento histórico.

Esse comportamento protecionista promove uma relativização das evoluções conceituais ocorrentes nestes círculos elitistas, situação esta que não permite, ao menos no curto prazo, a tramitação de conceitos e métodos entre perspectivas extremas do conhecimento (LAUDAN, 1996; KUHN, 1970). 
Tal isolamento epistemológico, em que cada abordagem busca conhecer o que há no mundo à sua maneira sem a consideração de vieses consideravelmente importantes, exige o que Lincoln e Guba (2006) denominam de exercício da interdisciplinaridade. Por ele, os estudos que se vinculam aos contextos organizacionais conseguem ter seus respaldos científicos continuamente reforçados. Sem uma efetiva relação de compartilhamento de conhecimentos não é possível um desenvolvimento teórico efetivo junto aos problemas de pesquisa investigados pela Administração.

Por tais considerações foi desenvolvido o presente artigo com o interesse de alcançar dois objetivos principais: (1) investigar as nuanças que um paradigma da sustentabilidade, como proposição de lente de observação da realidade para os contextos organizacionais deve assumir; e (2) apresentar e definir um paradigma da sustentabilidade, eclético, dialógico e flexível, por meio do qual o desenvolvimento sustentável possa ser assumido como um fenômeno de pesquisa coerente junto aos estudos organizacionais.

Mediante a necessidade de conceder resposta aos objetivos supramencionados foram selecionadas algumas contribuições específicas de discussões oriundas dos estudos organizacionais, de categorizações para análise do desenvolvimento sustentável e de posturas epistemológicas. Em relação aos estudos organizacionais foram selecionados os paradigmas sugeridos por Burrell e Morgan (1979), os pontos de interseção propostos por Reed (2007) e a segmentação teórica apresentada por Marsden e Townley (2001). No que concerne às categorizações para a análise do desenvolvimento sustentável foram escolhidas as correntes paradigmáticas abordadas por Gladwin, Kennelly e Krause (1995), a análise conceitual desenvolvida por Mebratu (1998) e a estrutura semântica do desenvolvimento sustentável conferida por Fergus e Rowney (2005) e Lélé (1991). Sobre as posturas epistemológicas, as que são privilegiadas por Denzin e Lincoln (2006) e Schwandt (2006) foram brevemente introduzidas, sendo elas: o positivismo, as filosofias interpretativistas e o construcionismo social.

Pelo caráter interdisciplinar extraído da relação entre todas as contribuições supramencionadas, a teoria do agir organizacional (MAGGI, 2003a) foi acatada como o corpo teórico que concede sustentação para esta vinculação entre desenvolvimento sustentável e estudos organizacionais por meio da proposição de um paradigma da sustentabilidade. Considerações sobre a diferença entre o desenvolvimento sustentável e a sustentabilidade são apresentadas na última seção do artigo, na qual será introduzido o paradigma discutido. 


\section{Metodologia}

No momento do desenvolvimento deste artigo, pensou-se muito sobre em como apresentar o objetivo maior deste texto, o qual gerou muitas inquietações pessoais e acadêmicas, tanto que elas confluíram na realização deste estudo. Apesar de muitas tentativas terem sido realizadas, outras palavras não puderam substituir a necessidade macro que conduziu o desenvolvimento desta pesquisa, ou seja, a de apresentar e definir um paradigma da sustentabilidade, para que, por meio desse paradigma, o desenvolvimento sustentável pudesse ser assumido como um fenômeno de pesquisa coerente para os estudos organizacionais.

Isso se justifica porque reconheceu-se que o objetivo apresentado é, por algumas perspectivas de compreensão da realidade e do conhecimento, amplo em sua natureza e complexo em sua proposição.

No entanto, ao ponderar que discussões, como as propostas aqui, ilustram a necessidade $e$ a urgência das ciências organizacionais assumirem sua representatividade teórica e empírica junto a esforços de pesquisas que primem pelo relacionamento das práticas de gestão e das rotinas organizacionais a ações efetivamente capazes de promover e evidenciar o alcance gradativo de um desenvolvimento sustentável, ou ao menos, o alcance do reconhecimento sobre a necessidade de promover esse tipo de desenvolvimento, estabeleceu-se que o risco de submissão deste artigo com as exatas palavras que expressavam o seu objetivo maior seria recompensador.

Se o primeiro objetivo busca apresentar e definir as nuanças de um "novo" paradigma, é necessário, antes, compreender a concepção de paradigma sobre a qual o desenvolvimento desta pesquisa se debruçou. Quando se fala em entender o que é um paradigma não há como fugir da definição concedida por Kuhn (1970).

De acordo com o autor, um paradigma é um corpo de ideias, assunções, conceitos, proposições, valores e objetivos de uma área substantiva $e$ influenciadora sobre como as pessoas observam o mundo, conduzem suas indagações científicas e aceitam formulações teóricas. O paradigma tradicional é a base que alicerça a ciência normal, ou, a ciência cotidiana. Essa ciência, no entanto, não consegue dar conta de todas as anomalias que se expressam em uma realidade especificamente explicada por ela, logo, os paradigmas existentes não conseguem manifestar compreensões significativas a respeito de todos os fenômenos. Quando essa situação ocorre, há uma 
ruptura científica, ao menos no imaginário acadêmico, a qual permitirá a abertura do sistema tradicional para a criação de um novo paradigma, que no tempo devido ocupará o lugar de paradigmas antigos (KUHN, 1970).

Por meio do artigo em apresentação não existe o intento de se descrever a construção social que deu luz ao que hoje é conhecido por desenvolvimento sustentável. Em verdade, a observação do desenvolvimento sustentável como um fenômeno necessário de ser pesquisado pelas organizações é uma premissa aceita como irrevogável para este estudo. O que se busca então? A resposta é clara, mas não simples. O que se busca é fundamentar um caminho teórico que permita iniciar a discussão para a formulação de um paradigma da sustentabilidade por meio de contribuições extraídas dos estudos organizacionais, de categorizações de análise para o desenvolvimento sustentável e de diferentes posturas epistemológicas.

Considera-se, assim, que a relação proposta (desenvolvimento sustentável e estudos organizacionais) simboliza uma das "áreas virgens" mencionadas por Astley $(1985,502)$. Virgem não no sentido de ineditismo, mas virgem no sentido de que embora já existam contribuições, elas ainda se declaram insuficientes para compreender realidades socialmente construídas específicas à Administração (ASTLEY, 1985). Por tal razão, os objetivos apresentados pediram a realização de uma pesquisa essencialmente teórica.

O caráter teórico do estudo determinou uma abordagem metodológica qualitativa, uma vez que ela é, segundo Richardson et al. (2008), uma forma adequada de entender a natureza de um fenômeno social. Pelo aspecto ressaltado por Astley (1985), tal pesquisa ficou enquadrada como exploratória, pois, também de acordo com as admoestações de Richardson et al. (2008), ela busca conhecer inicialmente as características de um fenômeno, para, posteriormente, procurar explicações de suas causas e consequências.

O Quadro 1 elenca quais os principais temas em análise neste artigo, o que se desejou investigar em cada um deles e os principais autores que contribuíram para a análise desses temas. 


\begin{tabular}{|c|c|c|}
\hline Temas & O que investigar? & O que investigar? \\
\hline $\begin{array}{c}\text { Abordagens } \\
\text { Organizacionais }\end{array}$ & $\begin{array}{l}\text { Um lócus paradigmático que caracterize o } \\
\text { desenvolvimento sustentável como } \\
\text { fenômeno coerente de ser pesquisado } \\
\text { pela Administração. }\end{array}$ & $\begin{array}{l}\text { Burrell; Morgan (1979) } \\
\text { Reed (2007) } \\
\text { Marsden; Townley } \\
\text { (2001) }\end{array}$ \\
\hline $\begin{array}{l}\text { Categorizações para o } \\
\text { Construto Desenvolvi- } \\
\text { mento Sustentável }\end{array}$ & $\begin{array}{l}\text { Modelos que classifiquem e analisem o } \\
\text { desenvolvimento sustentável por diferen- } \\
\text { tes abordagens e qualificações e que } \\
\text { venham de pesquisas constituídas com o } \\
\text { intuito de melhor compreender este } \\
\text { fenômeno. }\end{array}$ & $\begin{array}{l}\text { Fergus; Rowney (2005) } \\
\text { Gladwin; Kennelly; } \\
\text { Krause (1995) } \\
\text { Lélé (1991) } \\
\text { Mebtratu (1998) }\end{array}$ \\
\hline $\begin{array}{c}\text { Posturas } \\
\text { Epistemológicas }\end{array}$ & $\begin{array}{l}\text { Possíveis posturas epistemológicas que } \\
\text { propiciem um melhor relacionamento } \\
\text { entre o desenvolvimento sustentável e os } \\
\text { estudos organizacionais. }\end{array}$ & $\begin{array}{l}\text { Denzin; Lincoln (2006) } \\
\text { Schwandt (2006) }\end{array}$ \\
\hline $\begin{array}{l}\text { Teoria do Agir } \\
\text { Organizacional }\end{array}$ & $\begin{array}{l}\text { Uma teoria que sustente a } \\
\text { interdisciplinaridade do paradigma da } \\
\text { sustentabilidade. }\end{array}$ & $\begin{array}{c}\text { Maggi }(1984,2001 \\
2003 a, 2003 b)\end{array}$ \\
\hline
\end{tabular}

Quadro 1: Estrutura de investigação temática e procedimentos de pesquisa Fonte: Elaborado pelos autores

\section{Desenvolvimento Sustentável e Abordagens Organizacionais: em busca de um lócus paradigmático}

Frente ao anseio de responder ao primeiro objetivo proposto a este artigo foram abordados os paradigmas sugeridos por Burrell e Morgan (1979), os pontos de interseção propostos por Reed (2007) e a segmentação das teorias organizacionais apresentada por Marsden e Townley (2001). A seleção das contribuições desses autores, feita a partir dos critérios de abrangência da teoria e reconhecida coerência de suas ideias, se fez necessária para viabilizar a discussão proposta, uma vez que existem outras possibilidades de classificação dos paradigmas e inúmeras abordagens de interpretações da realidade.

O interesse de realização deste exercício analítico é identificar se o desenvolvimento sustentável se apresentaria como um fenômeno capaz de ser inserido em apenas um dos paradigmas, nos pontos de interseção e segmentação teórica estudados neste artigo, ou como um tema necessário de ser analisado por combinações diversas entre tais observações da realidade. 


\subsection{Os Paradigmas Sugeridos por Burrell e Morgan (1979)}

Um paradigma representa

[...] um conjunto básico de crenças que orientam a ação. Os paradigmas lidam com os primeiros princípios, ou os princípios fundamentais. São construções humanas que definem a visão de mundo do pesquisador como bricoleur interpretativo. (DENZIN; LINCOLN, 2006, p. 163).

Gibson Burrell (2007, p. 445) considera que os

[...] paradigmas definem, em um senso acordado e profundamente assentado, de uma forma de ver o mundo e como este deveria ser estudado, e que este ponto de vista é compartilhado por um grupo de cientistas que vivem em uma comunidade marcada por uma linguagem comum, que buscam fundar um edifício conceitual comum, e que são possuídos por uma postura política muito defensiva em relação aos de fora.

Na obra Sociological Paradigmsand Organizational Analysis, publicada originalmente em 1979, Burrell e Morgan (1979), a partir da análise de diversas vertentes de estudos organizacionais, sintetizaram quatro paradigmas (humanismo radical, estruturalismo radical, sociologia interpretativa e sociologia funcionalista) formados pela adoção de duas dimensões conceituais conflitantes básicas: sociologia da mudança radical versus sociologia da regulação; e objetivismo versus subjetivismo.

Dado que sociologia e teoria organizacional são partes não litigiosas da Ciência Social, qualquer afirmação feita nessas áreas, de natureza especulativa, precisa fazer suposições tanto sobre a natureza da sociedade, quanto sobre a natureza da ciência.

Se isso não for feito, consciente ou inconscientemente, então não está sendo feita uma afirmação da ciência social. Burrell e Morgan tentaram identificar a natureza dessas afirmações em dois eixos que, ao serem colocados em ângulo reto, criam quatro paradigmas mutuamente excludentes (BURRELL, 2007, p. 446). 
Esses paradigmas são detalhados no Quadro 2.

\begin{tabular}{|c|c|c|c|}
\hline $\begin{array}{c}\text { Sociologia } \\
\text { Funcionalista }\end{array}$ & $\begin{array}{c}\text { Sociologia } \\
\text { Interpretativista }\end{array}$ & $\begin{array}{c}\text { Humanismo } \\
\text { Radical }\end{array}$ & $\begin{array}{c}\text { Estruturalismo } \\
\text { Radical }\end{array}$ \\
\hline $\begin{array}{l}\text { O paradigma } \\
\text { funcionalista } \\
\text { representa a } \\
\text { perspectiva na qual } \\
\text { a sociologia da } \\
\text { regulação está } \\
\text { firmemente } \\
\text { enraizada e aborda } \\
\text { seus assuntos sob } \\
\text { uma visão } \\
\text { objetivista. }\end{array}$ & $\begin{array}{l}\text { O paradigma } \\
\text { interpretativo é } \\
\text { formado por uma } \\
\text { preocupação em } \\
\text { entender o mundo, } \\
\text { compreender a } \\
\text { natureza fundamen- } \\
\text { tal do mundo social } \\
\text { através de um } \\
\text { patamar da experi- } \\
\text { ência subjetiva. }\end{array}$ & $\begin{array}{l}\text { O paradigma } \\
\text { humanista radical é } \\
\text { definido pela sua } \\
\text { preocupação em } \\
\text { desenvolver uma } \\
\text { sociologia de mudan- } \\
\text { ça radical por um } \\
\text { ponto de vista } \\
\text { subjetivista. }\end{array}$ & $\begin{array}{l}\text { O paradigma } \\
\text { estruturalista radical } \\
\text { concentra-se na } \\
\text { mudança radical, } \\
\text { emancipação e } \\
\text { potencialidade, em } \\
\text { uma análise que } \\
\text { enfatiza conflito } \\
\text { estrutural, modos de } \\
\text { dominação, contradi- } \\
\text { ção e privação. }\end{array}$ \\
\hline
\end{tabular}

Quadro 2: Os paradigmas propostos por Burrell e Morgan (1979)

Fonte: Elaborado de acordo com as contribuições de Burrell e Morgan (1979)

Ainda que a obra de Burrell e Morgan (1979) seja muito criticada, de acordo com Burrell (2007, p. 446),

[...] o livro ressaltou a falência do campo da teoria organizacional com seus grupos conflitantes. Demonstrou que a orientação funcionalista, popular, politicamente superior e comum, não era de forma alguma a única estrada possível aberta para a análise organizacional.

Segundo Gil (2008), as origens do funcionalismo remetem aos positivistas Herbert Spencer e Émile Durkheim. Sua consolidação como método de investigação social, entretanto, ocorreu com Bronislaw Malinowki, para o qual o raciocínio básico do funcionalismo é:

[...] se os homens têm necessidades contínuas como uma conseqüencia de sua composição biológica e psíquica, então essas necessidades básicas irão requerer formações sociais que satisfaçam efetivamente tais necessidades (GIL, 2008, p. 19).

O funcionalismo se faz semelhante ao estruturalismo pelo fato de o cientista engajar-se totalmente com a ciência, todavia, para um estruturalista a 
ciência tem um fim diferente. O paradigma estruturalista radical advoga as teorias de mudança radical a partir de uma perspectiva objetivista. A dimensão desse paradigma centraliza-se na concepção materialista do mundo social, ligada por estruturas concretas e reais (GARCIA; MINUZZI, 2005). As autoras ainda complementam que o estruturalismo radical propõe uma crítica ao statu quo e sugere ao homem uma práxis política. Essa perspectiva compreende que as patologias sociais são produtos da desigualdade do poder na sociedade. Dessa situação emergem conflitos, tensões e desequilíbrios, os quais são solucionados por mudanças fundamentais nas formas como a sociedade está organizada e no modo como os seus recursos são distribuídos.

O estruturalismo radical, por conceder pouca relevância ao papel $e$ natureza do homem como ser individual, difere do humanismo radical que "[...] compreende a ordem social como sendo produto de coerção e não de consentimento" (GARCIA; MINUZZI, 2005, p. 2). A teoria crítica é o enfoque deste último paradigma. Para Lincoln e Guba (2006), essa teoria em si já é observada como um paradigma que em suas muitas formulações, articula uma ontologia baseada no realismo histórico, uma epistemologia transacional e uma metodologia que é tanto dialógica quanto dialética.

Garcia e Minuzzi (2005) afirmam que o paradigma humanista se relaciona ao paradigma interpretativo por meio de uma visão antipositivista do mundo social. O paradigma interpretativo opõe-se ao gerencialismo da teoria organizacional formal por seu alinhamento com a mudança social. Nesas mudança, as organizações são compreendidas como criações em vez de entidades naturais, logo, podem ser mudadas mediante a intervenção social. Esse paradigma defende que as organizações devem ser explicadas pelo conhecimento das intenções que fazem as pessoas agirem, e isso requer um conjunto de técnicas completamente diferente das utilizadas pelos pesquisadores organizacionais positivistas (MARSDEN; TOWNLEY, 2001).

\subsection{Os Pontos de Interseção de Reed (2007) e a Segmentação Teórica Proposta por Marsden e Townley (2001)}

Reed (2007) apresenta uma breve história dos estudos sobre as organizações. $\mathrm{O}$ autor distingue seis fases, nomeadas de modelo de metanarrativa interpretativa, expostas no Quadro 3. 


\begin{tabular}{|c|c|c|c|}
\hline $\begin{array}{c}\text { Modelo de } \\
\text { metanarrativa } \\
\text { interpretativa }\end{array}$ & $\begin{array}{c}\text { Problemática } \\
\text { principal }\end{array}$ & $\begin{array}{c}\text { Perspectivas ilustrativas/ } \\
\text { exemplos }\end{array}$ & $\begin{array}{l}\text { Transições } \\
\text { Contextuais }\end{array}$ \\
\hline Racionalidade & Ordem & $\begin{array}{l}\text { Teoria das organizações clássica, } \\
\text { administração científica, teoria } \\
\text { da decisão, Taylor, Fayol, Simon. }\end{array}$ & $\begin{array}{l}\text { de Estado guarda- } \\
\text { noturno a Estado } \\
\text { industrial }\end{array}$ \\
\hline Integração & Consenso & $\begin{array}{l}\text { Relações humanas, neo-RH, } \\
\text { funcionalismo, teoria da contin- } \\
\text { gência/sistêmica, cultura } \\
\text { corporativa, Durkheim, Barnard, } \\
\text { Mayo, Parsons. }\end{array}$ & $\begin{array}{l}\text { de capitalismo empre- } \\
\text { sarial a capitalismo do } \\
\text { bem-estar }\end{array}$ \\
\hline Mercado & Liberdade & $\begin{array}{l}\text { Teoria da firma, economia } \\
\text { institucional, custos de transa- } \\
\text { ção, teoria da atuação, depen- } \\
\text { dência de recursos, ecologia } \\
\text { populacional, teoria } \\
\text { organizacional liberal. }\end{array}$ & $\begin{array}{l}\text { de capitalismo } \\
\text { gerencial a capitalismo } \\
\text { neoliberal }\end{array}$ \\
\hline Poder & Dominação & $\begin{array}{l}\text { Weberianos neo-radicais, } \\
\text { marxismo crítico-estrutural, } \\
\text { processo de trabalho, teoria } \\
\text { institucional, Weber, Marx. }\end{array}$ & $\begin{array}{l}\text { de coletivismo liberal a } \\
\text { corporativismo } \\
\text { nefociado }\end{array}$ \\
\hline Conhecimento & Controle & $\begin{array}{l}\text { Etnométodo, símbolo/cultura } \\
\text { organizacional, pós-estruturalis- } \\
\text { ta, pós-industrialista, pós- } \\
\text { fordista/moderno, Focault, } \\
\text { Garfinkel, teoria do ator-rede. }\end{array}$ & $\begin{array}{l}\text { De industrialismo/ } \\
\text { modernindade a pós- } \\
\text { industrialismo/pós- } \\
\text { modernidade }\end{array}$ \\
\hline Justiça & Participação & $\begin{array}{l}\text { Ética de negócios, moralidade e } \\
\text { OB, democracia industrial, teoria } \\
\text { participativa, teoria crítica, } \\
\text { Habermas. }\end{array}$ & $\begin{array}{l}\text { de democracia repres- } \\
\text { siva a democracia } \\
\text { participativa }\end{array}$ \\
\hline
\end{tabular}

Quadro 3: Narrativas analíticas em análise organizacional

Fonte: Reed (2007, p. 65)

Marsden e Townley (2001) propõem um histórico da teoria organizacional dividido em dois momentos.

O primeiro consistiu na construção de uma teoria chamada de normal e um segundo resultou de manifestações de diversos autores e insatisfações também diversas, mas que é referido tendo sido desencadeado pelo pós-modernismo, 
que seria a teoria organizacional contranormal (BERTERO, 2001, p. 57).

Essas duas teorias são explicadas no Quadro 4.

Teoria organizacional normal

Positivista, objetivista, realista e voltada para a eficácia e para a eficiência. Seu modelo são as ciências de tipo duro, em que conhecimentos se provam empiricamente e há um processo de acumulação.

\section{Teoria organizacional contranormal}

Surgiu em função de diversas insatisfações com a teoria organizacional normal. A contrateoria organizacional não produziu até o momento alternativa à teoria organizacional normal porque se perdeu nas chamadas incomensurabilidades paradigmáticas, caindo num relativismo desesperador.

Quadro 4: Teorias organizacionais normal e contranormal

Fonte: Elaborado a partir das contribuições de Bertero (2001) e de Marsden e Townley (2001)

Bertero (2001, p. 58) admite que "[...] o mundo da teoria organizacional normal não foi sequer tocado ou abalado pelas críticas e propósitos da contrateoria". A teoria organizacional contranormal é, de acordo com Marsden e Townley (2001), rica em debates, diversa em contribuições e viva em expressar seu descontentamento à normalidade das proposições precursoras, todavia, distante da realidade organizacional, da prática e da gestão.

Essa consideração dos autores é rebatida por Bertero (2001, p. 59) que diz: "[...] não é apenas e nem principalmente da prática que conduz à aplicabilidade da teoria". O universo administrativista vai além da dicotomia teoria versus prática, uma vez que se preocupa em saber se a teoria, a teoria organizacional normal ou a contranormal e, também, se as ciências sociais podem explicar e, portanto, lastrear a prática, no sentido da ação humana.

Cabe aos pesquisadores pós-modernos a tarefa de extrair das discussões contranormais temas que possam ser explorados, em cotidianos organizacionais, por metodologias que avancem dos propósitos positivistas e objetivistas. A ciência organizacional se desenvolve a partir da observação das falhas da normalidade teórica anterior e do ajuste delas em novas proposições contranormais.

Vários temas interconectados orientam as contribuições analíticas oriundas das metanarrativas de Reed (2007) e da segmentação teórica defendida por Marsden e Townley (2001). Essas análises podem ser interpretadas como tentativas contestadas de representação e controle do entendimento da reali- 
dade em relação à prática social estratégica institucionalizada que é a organização. Reed (2007) admoesta que assim como o discurso da teoria política, o discurso da teoria da organização deve ser considerado uma rede contestável e contestada de conceitos e teorias, que travam batalhas para impor certos significados em detrimentos de outros ao entendimento partilhado da vida organizacional na modernidade recente. Essa concepção pode ser usada para mapear temas subjacentes às teorias organizacionais, e podem ser resumidos das seguintes formas:

[...] um debate teórico a respeito das explicações rivais sobre conceitos de 'atuação' e 'estrutura', à medida que estes são empregados como conceitos-chave de características organizacionais; um debate epistemológico entre 'construtivismo' e 'positivismo' e suas implicações para a natureza e caráter do conhecimento que os estudos organizacionais produzem; um debate analítico sobre a prioridade relativa a ser conferida, nos estudos organizacionais, ao nível 'local' em oposição ao nível 'global' de análise; um debate normativo entre o 'individualismo' e 'coletivismo' como concepções ideológicas rivais, que competem pela noção de 'viver bem' nas sociedades modernas (REED, 2007, p. 82).

Os debates que compõem os pontos de interseção de Reed (2007) são explorados no Quadro 5. 


\begin{tabular}{|c|c|c|c|}
\hline $\begin{array}{l}\text { O debate teóri- } \\
\text { co atuação/ } \\
\text { estrutura }\end{array}$ & $\begin{array}{c}\text { O debate } \\
\text { epistemológico } \\
\text { construtivista/ } \\
\text { positivista }\end{array}$ & $\begin{array}{c}\text { O debate analíti- } \\
\text { co local/global }\end{array}$ & $\begin{array}{c}\mathrm{O} \text { debate } \\
\text { normativo indivi- } \\
\text { dualista/ } \\
\text { coletivista }\end{array}$ \\
\hline $\begin{array}{l}\text { Os que enfatizam a } \\
\text { atuação concen- } \\
\text { tram-se na busca de } \\
\text { um entendimento } \\
\text { da ordem social e } \\
\text { organizacional que } \\
\text { saliente as práticas } \\
\text { sociais por meio das } \\
\text { quais seres huma- } \\
\text { nos criam e repro- } \\
\text { duzem instituições. } \\
\text { Os que privilegiam } \\
\text { a estrutura ressal- } \\
\text { tam a importância } \\
\text { dos padrões e das } \\
\text { relações externas } \\
\text { que determinam e } \\
\text { circunscrevem a } \\
\text { interação social } \\
\text { dentro de formas } \\
\text { institucionais } \\
\text { específicas. }\end{array}$ & $\begin{array}{l}\text { O primeiro promove } \\
\text { uma concepção da } \\
\text { organização como } \\
\text { sendo um artefato } \\
\text { socialmente } \\
\text { construído e } \\
\text { dependente, que } \\
\text { somente pode ser } \\
\text { entendido em } \\
\text { termos de conven- } \\
\text { ções metodológicas } \\
\text { altamente restritas e } \\
\text { localizadas, sempre } \\
\text { abertas a revisões e } \\
\text { mudanças. O } \\
\text { segundo trata a } \\
\text { organização como } \\
\text { um objeto ou } \\
\text { entidade existindo } \\
\text { como tal, e que } \\
\text { pode ser explicada } \\
\text { em termos de } \\
\text { princípios gerais de } \\
\text { leis que governam } \\
\text { seu funcionamento. }\end{array}$ & $\begin{array}{l}\text { O debate micro/macro } \\
\text { questiona se a ênfase } \\
\text { deve ser dada aos } \\
\text { aspectos íntimos e } \\
\text { detalhados da } \\
\text { conduta individual ou } \\
\text { em fenômenos } \\
\text { impessoais, de maior } \\
\text { escala. }\end{array}$ & $\begin{array}{l}\text { O individualismo } \\
\text { oferece uma visão da } \\
\text { organização como } \\
\text { uma criação não } \\
\text { intencional dos } \\
\text { atores individuais } \\
\text { que seguem os } \\
\text { desígnios de seus } \\
\text { objetivos políticos e } \\
\text { instrumentais. O } \\
\text { coletivismo trata a } \\
\text { organização como } \\
\text { uma entidade } \\
\text { objetiva que se } \\
\text { autoimpõe aos } \\
\text { atores com tal força } \\
\text { que lhes deixa pouca } \\
\text { ou nenhuma } \\
\text { alternativa, exceto } \\
\text { obedecer a seus } \\
\text { comandos. }\end{array}$ \\
\hline
\end{tabular}

Quadro 5: Os pontos de interseção de Reed (2007)

Fonte: Elaborado de acordo com as contribuições de Reed (2007)

A exposição das consequentes metanarrativas, paradigmas e pontos de inserção, frente às teorias normais e contranormais, permitem uma melhor compreensão de tudo o que tem sido discutido até o momento.

As narrativas racional, integracionista e de mercado apoiam firmemente a concepção estrutural da organização, se desenvolveram com base na ontologia realística e na epistemologia positivista e priorizam uma concepção mais global da realidade da organização. Os pesquisadores que trabalham segundo as tradições de poder, conhecimento e justiça preferem o con- 
ceito de atuação organizacional, são mais favoráveis a uma ontologia construtivista e a uma epistemologia convencionalista e tendem a dar destaque a processos e práticas organizacionais em nível local/micro.

Em relação ao último debate, por meio das contribuições de Reed (2007), afirma-se que as narrativas racional, integracionista e de mercado assumem uma perspectiva normativa individualista, já que as narrativas de poder, conhecimento e justiça se alinham a um debate mais coletivista.

Pelas considerações de Marsden e Townley (2001) e de Reed (2007) é possível esclarecer que as teorias organizacionais normais são compostas pelas metanarrativas racional, integrativa e de mercado, e que as teorias organizacionais contranormais são representadas pelas metanarrativas de poder, conhecimento e justiça.

\section{Categorizações para a Análise do Construto Desenvolvimento Sustentável}

A nomeação de cada uma dessas categorizações tem como intuito final alcançar uma qualificação paradigmática que melhor vincule o desenvolvimento sustentável como fenômeno de pesquisa coerente junto aos estudos organizacionais.

Em face dessa busca, toma-se o discurso de Morgan (1980) que, antecipadamente, avisou sobre o fato dos cientistas organizacionais estarem aprisionados em uma série de constrições equivocadas a respeito do status ontológico da realidade social e da natureza humana, e, em razão dessa realidade, percebe-se a necessidade de se adotar uma perspectiva mais cosmopolita nas teorizações organizacionais, buscando alcançar avanços efetivos.

Gladwin, Kennelly e Krause (1995) concordam com Morgan (1980) ao afirmarem que o domínio organizacional, para tratar dos problemas relacionados ao desenvolvimento sustentável, está isolado e fraturado por uma profunda crise epistemológica provocada pela simples ação de dissociar a humanidade (com suas respectivas organizações) do restante da realidade, também amparada pelo mundo natural.

No intuito de averiguar tais críticas foram investigadas algumas categorizações do desenvolvimento sustentável. Sabe-se da existência de inúmeras, mas para que a viabilidade do presente estudo fosse garantida, optou-se por três contribuições específicas, sendo elas: as correntes 
paradigmáticas abordadas por Gladwin, Kennelly e Krause (1995), a análise conceitual de Mebratu (1998) e a estrutura semântica do termo conferida por Lélé (1991) e Fergus e Rowney (2005). Esses modelos analíticos são abordados em sequência.

\subsection{As Correntes Paradigmáticas Abordadas por Gladwin, Kennelly e Krause (1995)}

Gladwin, Kennelly e Krause (1995) em uma tentativa de estabelecer um paradigma que viabilizasse o tratamento do desenvolvimento sustentável por abordagens organizacionais, realizaram um exercício comparativo entre três correntes, sendo que duas delas (o tecnocentrismo e o ecocentrismo) são abordagens extremamente opostas, enquanto a terceira (o sustaincentrism - paradigma centrado na sustentabilidade) representa uma compreensão de mundo mais flexível e aberta. Essas correntes paradigmáticas são apresentadas com maiores detalhes (GLADWIN; KENNELLY; KRAUSE, 1995):

a) O tecnocentrismo. As origens deste paradigma podem ser remetidas à revolução científica do Século XVII, com a emergência de uma teoria social liberal, da racionalidade da mão invisível proposta por Adam Smith (ROTHSCHILD, 2003), e da tendência de privilegiar os seres humanos sobre a natureza. Essa perspectiva ainda se faz dominante contemporaneamente, uma vez que suas proposições são mais convidativas aos sistemas econômicos e aos modelos de gestão organizacionais.

b) $\mathbf{O}$ ecocentrismo. Os adeptos deste paradigma provêm de uma filosofia que apregoa um estilo de vida que se conforme com a ordem da natureza, com a reverência ao planeta, assim como os movimentos transcedentalistas e preservacionistas. Este paradigma é marcado por contribuições advindas da ecologia profunda, vertente sociológica que rejeita qualquer dominação humana sobre a natureza.

c) O sustaincentrism. A noção de um paradigma interessado com o desenvolvimento sustentável pode ser compreendida como um esforço dialético. Embora os paradigmas tecnocêntrico e ecocêntrico possuem uma longa história, o paradigma da sustentabilidade ain- 
da é embrionário. A articulação de um olhar de mundo centrado na sustentabilidade deve ser visto como uma tentativa de se buscar uma reconciliação entre posições científicas tão radicais.

É possível vislumbrar que tanto o tecnocentrismo quanto o ecocentrismo falham em oferecer uma base sobre a qual o desenvolvimento sustentável possa ser investigado. Ambos os paradigmas, ao promoverem suas premissas por métodos radicais e isolados não conseguem sequer promover o desenvolvimento e muito menos preservar a natureza (GLADWIN; KENNELLY; KRAUSE, 1995).

O paradigma centrado na sustentabilidade assume uma responsabilidade de articular o conhecimento $e$ as discussões por uma abordagem interdisciplinar, por meio da qual deve ser estabelecido um diálogo entre essas duas fortes perspectivas científicas e operacionalizar um modelo que melhor entenda e promova o desenvolvimento sustentável.

\subsection{A Análise Conceitual de Mebratu (1998)}

Desde que a definição de desenvolvimento sustentável, concedida pela World Comissionon Environmentand Development - WCED, em 1987, se popularizou, inúmeros esforços têm sido realizados por inúmeros grupos de pesquisa, organizações e movimentos sociais com o intuito de capturar a verdadeira essência desse conceito. Embora seja uma tarefa complexa dar conta de todas as definições, Mebratu (1998) categoriza essas definições em três versões principais: a versão institucional, a versão ideológica e a versão acadêmica. Todas melhor exploradas em sequência (MEBRATU, 1998):

a) Versão institucional. Esta versão se preocupa em analisar definições concedidas por instituições, tais como a WCED, o International Instituteof Environmentand Development - IIED e a World Business Council for Sustainable Development -WBCSD. Os adeptos desta versão consideram que a comparação das definições concedidas por tais instituições participam de uma mesma essência, a de se preocupar com a satisfação das necessidades. Esta versão, em síntese, afirma que um crescimento econômico saudável, responsável e limpo ainda é o principal desafio para um desenvolvimento efetivamente sustentável. 
b) Versão ideológica. Predominam nesta versão as ideologias clássicas, tais como teoria da libertação, o feminismo radical e o marxismo. Inseridos nesta versão estão os movimentos ecofeministas, ecossocialistas e ecoteólogos. O ecofeminismo é considerado como a conjuntura conceitual que une os quatro pilares da teoria da libertação: aqueles relacionados às opressões de gênero, à raça, à classe e à natureza. $\mathrm{O}$ ecossocialismo é alicerçado na afirmativa de que um desenvolvimento sustentável e ecológico jamais poderá ser alcançado por meio de ações inseridas em um sistema capitalista. A ecoteologia fundamenta-se na crença de que a humanidade ignorou a importância dos patrimônios ecológicos em suas tradições religiosas.

c) Versão acadêmica. Na versão acadêmica, as concepções econômicas, ecológicas e sociológicas refletem a responsabilidade da comunidade científica perante o desafio da crise ambiental. Os economistas, por consequência da abordagem neoclássica dominante, querem transformar o ambiente em uma commodity para que assim ele possa ser analisado em termos monetários. Para os ecologistas duas premissas precisam ser identificadas para o acontecimento da sustentabilidade: primeira, a natureza, se não invadida, é um sistema auto-organizado que se transforma e responde a diversas condições quase estáveis; segundo, os seres humanos dependem desse sistema pela necessidade de suprimento de alguns recursos para a produção de alimentos e demais artigos de uso imprescindível para a humanidade. A sociologia se aproxima das contribuições da ecologia.

Existe um pré-conceito concedido à versão acadêmica. Redclift e Benton (1994) consideram que por ela promover a interdisciplinaridade tão aceita em relação ao desenvolvimento sustentável, pode ser ela a culpada por esta miscelânea de definições equivocadas encontradas em diversos trabalhos científicos. Os mesmos autores consideram que essa versão possui fundamentações epistemológicas reducionistas, traduzidas por suas proposições equivocadas.

Já Tryzna (1995) não hesita em dizer que a fonte dessa discriminação está no fato de cada abordagem racional participar de um movimento radical 
próprio, por meio do qual existe uma tendência de se menosprezar as demais abordagens ao qualificá-las como reducionistas e fracas. Para o autor cada abordagem assume, consciente ou inconscientemente, a tentativa de obrigar a sociedade a aceitar suas proposições como uma verdade inquestionável.

\subsection{A Estrutura Semântica do Termo Conferida por Fergus e Rowney (2005) e Lélé (1991)}

Esse modelo se preocupa em investigar as raízes semânticas do termo "desenvolvimento sustentável", uma vez que esse exercício auxilia a explicar os entendimentos contraditórios referentes a essa expressão. Lélé (1991) nota que o termo é interpretado de maneira inconsistente, assim como um crescimento sustentável (esse termo também é definido por Leff (2008) como crescimento sustentado), ou como uma forma de mudança social que, junto aos objetivos desenvolvimentistas atuais tem o objetivo adicional de alcançar uma sustentabilidade ecológica.

Embora Fergus e Rowney (2005) discordem quanto a algumas etapas oferecidas por Lélé (1991) em referência ao processo de estruturação semântica do termo "desenvolvimento sustentável", eles não se contrariam.

Resumidamente esses autores partem do princípio que a soma das palavras sustentar (conservar ou prorrogar) e desenvolver (partir de resultados anteriores ou transformar o uso de algo) formam a expressão "desenvolvimento sustentável" (manter os resultados passados ou transformar o uso dos recursos). Esse termo, para os autores, representa a direção futura do progresso humano, por meio de processos que ativem três esferas principais: a economia, a ecologia e a sociedade. Quando a economia se alia à ecologia o desenvolvimento sustentável é aceito como um objetivo, e definido como um meio para o progresso humano por uma abordagem integrativa e inclusiva para as gerações contemporâneas e futuras. Quando as perspectivas ecológicas se somam às sociais, o desenvolvimento sustentável é assumido como um fenômeno processual e entendido como um discurso que integra conhecimentos, filosofias e ferramentas de mensuração altamente eficazes. Se colocado sob uma lente amparada pelo paradigma dominante (tecnocentrismo), o desenvolvimento sustentável como objetivo é interpretado como um crescimento sustentável, já que o processo é interpretado como um debate sobre os processos científicos e as metodologias, nos quais o sucesso é mensurado 
por retornos financeiros, tidos como referências para a tomada de qualquer decisão (FERGUS; ROWNEY, 2005; LÉLÉ, 1991).

Apresentados os modelos de categorização do desenvolvimento sustentável, passa-se para a discussão de possíveis posturas epistemológicas que selecionem qualificações necessárias ao paradigma da sustentabilidade, ou seja, aquele que viabiliza uma compreensão do desenvolvimento sustentável como um fenômeno de pesquisa coerente para os estudos organizacionais.

\section{Posturas Epistemológicas para a Compreensão do Desenvolvimento Sustentável}

Nesta seção serão abordadas discussões sobre algumas posturas epistemológicas que possam auxiliar o processo de definição do termo "desenvolvimento sustentável". Ressalta-se que o que se investiga é um significado coerente com as proposições das ciências organizacionais. De acordo com Denzin e Lincoln (2006), um paradigma é um conceito macro composto por quatro microconceitos, a saber: a ética, a epistemologia, a ontologia e a metodologia.

A ética questiona: como serei enquanto pessoa moral no mundo? A epistemologia: como conheço o mundo? Qual a investigação entre o investigador e o conhecido? [...] A ontologia levanta questões básicas a respeito da natureza da realidade e da natureza do ser humano no mundo. A metodologia concentra-se nos melhores meios para a aquisição do conhecimento sobre o mundo (DENZIN; LINCOLN, 2006, p.163).

Desse conceito extrai-se a parte referida à epistemologia, mais em específico a pergunta: Como conheço o mundo? O que se intenta por essa seleção é investigar como o desenvolvimento sustentável, como fenômeno de interesse aos estudos organizacionais, pode assumir uma postura epistemológica coerente nas pesquisas relacionadas às organizações.

Mediante esse recorte, inicia-se uma investigação sobre o conceito do termo "desenvolvimento sustentável" por três posturas epistemológicas apresentadas por Denzin e Lincoln (2006) e Schwandt (2006): positivismo e empirismo lógico, interpretativismo e o construcionismo social. 
Em sentido amplo, a epistemologia é conceituada como o estudo metódico e reflexivo da ciência, de sua organização, de sua formação, do seu funcionamento e produtos intelectuais. O papel e a contribuição de uma instância epistemológica para a pesquisa podem ser considerados a partir de duas funções: por um lado assume a condição de metaciência, porque vem após e diz respeito às ciências e por outro revela um caráter intracientífico $e$ representa uma instância intrínseca à produção científica. Etimologicamente, epistemologia significa discurso (logos) sobre a ciência (episteme) (MARTINS; THEÓPHILO, 2007).

Em relação ao desenvolvimento sustentável, segundo Fergus e Rowney (2005), nota-se um discurso dominante, sobre o qual o mundo é objetivo, mensurável e compreensível. A verdade, portanto, se torna atingível por meio de metodologias já existentes e comunicadas por regras já institucionalizadas. Não existe espaço para o conhecimento baseado em uma visão subjetiva do mundo, cuja intuição e experiência do mundo natural representariam os principais elementos para a geração de novos conhecimentos.

Para tanto, apresenta-se no Quadro 6, uma síntese das posturas epistemológicas mencionadas de acordo com Denzin e Lincoln (2006) e Schwandt (2006) e seus possíveis desmembramentos. A seleção das posturas epistemológicas apresentadas em sequência ocorreu em decorrência de serem estudadas pelos autores supramencionados, logo, esse foi o filtro utilizado para selecionar quais seriam as abordagens epistemológicas mencionadas neste estudo.

Muitas são as perspectivas epistemológicas defendidas por cada uma das linhagens científicas que adotam, ontologicamente, uma posição diferenciada de observar o mundo e o que nele há. Mais uma vez, por esse recorte, busca-se conceder viabilidade de resposta aos objetivos desta pesquisa e não negar de maneira alienada toda uma série de proposições e argumentações presentes em outras epistemologias.

Estudos futuros podem contemplar as proposições aqui apresentadas por meio de raízes epistemológicas não contempladas, uma vez que, o que está sendo proposto, ou seja, o paradigma em apresentação é, antes de mais nada, passível de ser reconstruído pelas sugestões e críticas advindas daqueles que buscam pesquisar o mesmo tema. 
Os defensores do positivismo se mantêm fiéis à idéia de que a finalidade de qualquer ciência é oferecer explicações causais de fenômenos sociais, comportamentais e físicos. As filosofias do positivismo lógico e do empirismo lógico tinham como principal preocupação a reconstrução racional do conhecimento científico por meio da análise semântica e sintática de dois tipos de declarações científicas (as declarações que explicam, isto é, as teorias e as hipóteses, e as declarações que descrevem, ou seja, as observações). Para os positivistas as dimensões sociais, culturais e históricas da compreensão eram consideradas extracientíficas e, por isso, irrelevantes para qualquer relato epistemológico válido do que constitui o conhecimento científico genuíno e sua justificação. O empirismo lógico trabalhava a partir de uma concepção do conhecimento como representação correta de uma realidade independente e o seu interesse era, $e$ é, quase que exclusivamente voltado à questão do estabelecimento da validade das alegações de conhecimento.

Identificação Empática. Essa postura interpretativista (também chamada de intencionalismo) descreve o que constitui o conhecimento histórico, encontrando-se também ao centro do que é conhecido como hermenêutica objetivista ou conservadora. Essas duas abordagens têm em comum a idéia geral de que é possível transcender as circunstâncias históricas, ou escapar delas, a fim de reproduzir o significado.

Sociologia Fenomenológica. A análise fenomenológica interessa-se principalmente em compreender a constituição do mundo intersubjetivo, cotidiano. Dois instrumentos conceituais geralmente empregados nessa reconstrução são a indexicalidade e a reflexividade. A primeira indica que o significado de uma palavra ou enunciado é dependente de seu contexto de utilização. A segunda direciona a atenção para o fato de que os enunciados não são apenas sobre algo, mas também fazem algo; um enunciado compõe, em parte, um ato de fala.

Hermenêutica Filosófica. Esta perspectiva desafia, de diversas maneiras, o retrato epistemológico cartesiano defendido pelas demais vertentes da filosofia interpretativista. Seus defensores sustentam que a compreensão não é, em primeiro lugar, uma tarefa controlada por procedimentos ou regras, mas, sim, justamente, uma condição do ser humano. A compreensão é a interpretação. Nesta perspectiva entende-se que a tradição não é algo externo, objetivo e pertencente ao passado, ela requer o engajamento das tendenciosidades do indivíduo. A compreensão é participativa, convencional e dialógica, assim, se assume uma visão não objetivista do significado. Em outras palavras, o significado é negociado mutuamente no ato da interpretação e não simplesmente descoberto.

Em um sentido quase imperceptível todos os seres humanos são construtivistas, caso acreditem que a mente está ativa na construção do conhecimento. Na epistemologia contemporânea esse senso comum do construcionismo é também chamado de perspectivismo. É a visão de que todas as alegações de conhecimento e a avaliação destas ocorrem dentro de um esquema conceitual através do qual o mundo é descrito e explicado. As filosofias do construcionismo social rejeitam a visão realista e ingênua da representação, mas geralmente avançam muito mais na negação de todo e qualquer interesse em uma ontologia do real.

Quadro 6: As quatro posturas epistemológicas para a definição do desenvolvimento sustentável

Fonte: Schwandt (2006, p. 195-202) 
Essas posturas epistemológicas representam diferentes maneiras de como um fenômeno de pesquisa percebe o mundo a sua volta. Elas se aliam em alguns pontos, mas divergem completamente em outros.

A hermenêutica objetivista e a hermenêutica filosófica iniciaram-se como movimentos simultâneos na Alemanha no início dos anos de 1980. Nessa época, a pesquisa qualitativa era cada vez mais aceita como um processo contínuo de construção de versões da realidade, bem por isso havia uma acepção nas pesquisas de uma mistura de gêneros, as quais caracterizavam os avanços científicos. Assim, diversos modelos e interpretações teóricas dos objetos e dos métodos resistiam lado a lado e, a partir deles, os pesquisadores assumiam o poder de escolher e comparar diferentes formas de se observar o mundo, tal como o interacionismo simbólico, a etnometodologia, a fenomenologia, a semiótica e o feminismo. Por esse contexto, as "hermenêuticas" surgiram com o intuito de investigar se tais avanços teóricos poderiam ser vistos como modismos, tendências ou recomeços (FLICK, 2009).

Para a hermenêutica objetivista, também denominada de hermenêutica estrutural, as intenções subjetivas relacionadas às pesquisas são consideradas como irrelevantes, enquanto para a hermenêutica filosófica o que interessa é a subjetividade da construção social do conhecimento (FLICK, 2009). A hermenêutica objetivista, então, compartilha de uma mesma epistemologia com o interpretativismo, ao passo que a hermenêutica filosófica rejeita completamente essa vertente (SCHWANDT, 2006).

A hermenêutica filosófica e as filosofias dos construcionistas sociais (assim como as abordagens desconstrucionistas, da teoria crítica e algumas feministas e neopragmáticas) têm precedentes no amplo movimento de afastamento do relato empírico, lógico atomístico, designativo, representacional do significado e do conhecimento (SCHWANDT, 2006). Os construcionistas rejeitam o positivismo e se preocupam em analisar a relação com a realidade ao tratarem os processos construtivos de suas abordagens (FLICK, 2009).

As opiniões construcionistas sociais se compartilham com a hermenêutica filosófica em questões relacionadas à crítica geral do significado como objeto, revelando uma afinidade com a noção do nascimento do significado. No entanto, a similaridade termina nesse ponto. Embora seja construcionista em sua negação a uma teoria objetivista do significado, a hermenêutica filosófica confia no potencial da linguagem para revelar o significado e a verdade enquanto os construcionistas sustentam que não existe nenhuma verdade em relação à questão da interpretação. Pela força da 
hermenêutica filosófica, alguns autores já a consideram um movimento separado da filosofia interpretativista. E pela persistência do positivismo, ele permanece como uma epistemologia isolada sem qualquer relacionamento com as demais posturas (DENZIN; LINCOLN, 2006; SCHWANDT, 2006).

Apresentados os alicerces sobre os quais se desenvolveram o paradigma da sustentabilidade apresenta-se em sequência, de maneira breve, a teoria organizacional que melhor dialoga com toda a interdisciplinaridade proposta.

\section{A Teoria do Agir Organizacional e a Lógica das Competências}

Quando uma teoria é escolhida como referência para explicar, ou ainda, para conduzir a explicação e a investigação do fenômeno em estudo corre-se o risco de, por uma consciência alienada, ou por uma inconsciência desalienada, se rejeitar um corpo teórico mais completo, dotado de raízes epistemológicas mais coerentes para com aquilo que se intenta investigar.

A afinidade científica com os preceitos ofertados em uma teoria específica faz com que ela se torne e se comprove como superior, apenas para quem a deseja utilizar, logo, a escolha de uma referência teórica padrão está impregnada pela própria teoria que será (ou já foi) escolhida. Nesse sentido, apesar de científica em seus atributos ontológicos, epistemológicos e metodológicos, no que se refere à sua adoção como padrão de orientação em um estudo específico, a teoria apenas se pretende científica (KUHN, 1970; LAUDAN, 1996).

A subjetividade envolta ao processo de escolha e definição de uma teoria foi exposta, uma vez que é necessário assumir que dentre muitas teorias organizacionais existentes apenas uma será abordada como possível de fundamentar toda a relação em proposição (desenvolvimento sustentável e estudos organizacionais). A subjetividade não é um sinônimo de fragilidade, mas sim, é o ato de reconhecer que a realidade e a possibilidade de explicála é tão ampla que, mediante tal complexidade, a racionalidade humana limitada necessita de alguns recortes que permitam que o teor holístico do mundo seja gradativamente assimilado por quem o pesquisa (POPPER, 1985; MATTOS, 2009). 
Por meio do exposto e com o intuito de validar a vinculação entre o desenvolvimento sustentável e os estudos organizacionais introduz-se a teoria do agir organizacional.

A perspectiva epistemológica que conduz os preceitos fundamentais da teoria do agir organizacional rejeita o positivismo e o antipositivismo, por ser, de acordo com Maggi (2003a), tanto uma teoria do agir social quanto uma teoria do agir racional.

$\mathrm{O}$ agir social indica um agir provido de um sentido intencionado, por meio do qual um ou mais sujeitos, se relaciona $(\mathrm{m})$ e se respalda $(\mathrm{m})$ no agir de outros sujeitos. O agir organizacional abrange os processos de ação singular e coletiva, não obstante, todo processo organizacional guarde relação com outros processos. O agir racional valida a ideia de que o agir organizacional ordena as ações processuais em direção a um objetivo perseguido, mas esse agir racional, ainda que inconscientemente, é intencional e limitado como a razão humana (MAGGI, 1984; 2001; 2003a 2003b).

A teoria do agir organizacional, então, exprime uma maneira de ver e de conceber os fenômenos organizacionais. Esse corpo teórico entende a organização como agir social, como processo de ações e decisões. Ele não separa a organização dos sujeitos agentes que atuam e desenvolvem o processo. A interpretação abrange a compreensão do sentido do agir e sua explicação em termos de causa adequada no desenrolar do processo ao longo do tempo (MAGGI, 1984; 2003b).

Por meio das proposições de Maggi (2001; 2003a) compreende-se que o agir organizacional é um acontecimento macro e consequente de inúmeros processos micros, sendo eles internos e externos à organização. Esses processos, para serem efetivamente realizados, precisam ser compreendidos pelos indivíduos que o realizarão e participarão deles. Essa compreensão é admitida como a ação principal de qualquer procedimento organizacional. O compreender, no entanto, precisa ser comprovado, caso contrário torna-se uma adversidade para toda a cadeia de ações dependentes. Essa validação está relacionada em parte com o empirismo organizacional, mas também se relaciona com a riqueza da subjetividade das relações organizacionais. A causalidade dos relacionamentos organizacionais, portanto, somente acontece pela compreensão das ações individuais, as quais comungam de um espaço simultaneamente hipotético e real. Entre essa interligação do que existe e do que se deseja, alcança-se uma rede sistêmica de ações traduzida como o agir organizacional (MAGGI, 1984; 2001; 2003a; 2003b). 
Sendo a teoria do agir organizacional, também, uma teoria do agir social, tem-se como imprescindível a compreensão desse agir social. $\mathrm{O}$ agir social é emanado por uma humanidade cujas ações são em grande parte não lógicas, ou até mesmo, reflexivas. Essa distância do concreto não classifica o agir humano como irreal, pois é pelos momentos de abstração que se alcançam considerações de como agir ou decidir em relação a algo. Decisão e ação são atos findos, mas não finitos, ou seja, a realização dos mesmos, ainda que reversível, deixa um histórico, bem por isso almejam ser proferidos por uma certeza indubitável. Certeza, de acordo com a teoria do agir organizacional, nada mais é do que uma incerteza reduzida sobre uma realidade observável e totalmente influenciável pelos indivíduos que procuram estabelecer posições de dominação em processos de negociação. Se o processo é influenciável também é conflituoso, e tal conflito, ainda que dentro de uma organização, representa uma desordem social oriunda de uma dimensão social maior. Considera-se como maior dimensão a sociedade, que para conter seus conflitos e adversidades procura por regras, as quais podem ser impostas ou negociadas. As regras, normas e demais meios de regulação são tendenciosos, uma vez que constituem uma ação racional tomada $e$ decidida por alguns indivíduos que visam um benefício social ou individual futuro. Esta lógica de ação, qualificadamente complexa, ainda que estruturada com os mais profundos detalhes, é intencional, uma vez que os indivíduos sabem o que querem, e limitada, assim como a razão humana. Toda essa complexidade de relações é compreendida como o agir social (MAGGI, 1984; 2003b).

Definidos o agir organizacional e o agir social, admite-se que não há como definir qual participa de maior relevância. Esses "agires" são simultâneos e interdependentes, logo, considera-se que as sociedades estão impregnadas pelo agir organizacional e que as organizações estão imersas no agir social. Um alimenta ou destrói o outro, de acordo com a intencionalidade do sistema e da força da comunicação informal das dimensões sociais. O sistema apenas alia o agir organizacional ao agir social e, vice versa, quando a cooperação se manifesta nas realidades sociais. A cooperação influencia o poder das ações, que por consequência influencia a efetividade das decisões, que por sua vez influencia as estratégias organizacionais e os relacionamentos sociais (MAGGI, 1984; 2000; 2001; 2003a; 2003b).

Nesse contexto, o desenvolvimento sustentável, junto aos estudos organizacionais, pode ser compreendido como um agir organizacional, ou 
seja, um agir social circunscrito. Trata-se, portanto, de um fenômeno social de extrema relevância para as organizações. Por meio de discussões vinculadas ao desenvolvimento sustentável é promovido o interesse das organizações em alcançá-lo por vias de regulação (obrigatoriedade/imposição) ou por pró-atividade (voluntarismo).

Trata-se, também, de um fenômeno possível de ser analisado em um contexto organizacional com elevada importância para a sociedade, a qual passa a exigir mecanismos de gestão orientados para o desenvolvimento sustentável.

\section{O Paradigma da Sustentabilidade}

Após a inserção do termo desenvolvimento sustentável no cenário internacional, observou-se uma falta de consenso sobre o que realmente tal expressão poderia significar e também sobre o que diferencia o desenvolvimento sustentável da sustentabilidade. Essas são algumas das principais indagações a serem respondidas por meio da presente seção, respostas necessárias para a apresentação do paradigma da sustentabilidade. Justifica-se esta preocupação pelo fato de que se não for mantida uma coerência discursiva, corre-se o risco de se ceder à generalidade e à ambiguidade observada no relacionamento das palavras "desenvolvimento" e "sustentabilidade" (LÉLÉ, 1991).

Tais discussões tornaram-se mais intensas a partir do ano de 1980, com o lançamento do World ConservationStrategy - WCS, por meio do qual muitos começaram a tentar definir o desenvolvimento sustentável como um fenômeno necessário de ser expresso em outras palavras (TRYZNA, 1995). Dentre as incontáveis nomenclaturas concedidas destacam-se: um valor de transformação (CLARK, 1989), reorganização social (GORE, 1992), uma expressão visionária (LEE, 1993), desenvolvimento moral (ROLSTON, 1994) e processo ininterrupto de transformações (VIEDERMAN, 1994). Todas essas terminologias ramificaram-se, principalmente, do conceito de desenvolvimento sustentável apresentado pela Comissão de Brundtland (WCED, 1987), o qual de acordo com Gladwin, Kennelly e Krause (1995) foi amplamente aceito por milhares de organizações governamentais, empresas e instituições internacionais, por uma assimilação normativa e abstrata desprovida de qualquer interesse de investigar a essência do conceito em perspectiva. 
Osorio, Lobato e Castillo (2005) combatem essa generalização ao afirmar que as discussões em torno de um debate conceitual não podem ser aceitas como algo óbvio e proveniente de propostas simplistas compostas por definições não muito detalhadas e deficientes de complexidade. De acordo com os autores, assim acontece com o desenvolvimento sustentável e com a sustentabilidade, que se tornaram meras expressões inseridas em um processo inconsciente de homogeneização global.

Ao investigar mais profundamente o conceito de "sustentabilidade", Osorio, Lobato e Castillo (2005) consideram que ele é dividido em duas vertentes principais: normativa e positiva. A primeira refere-se ao que deveria ser feito e a segunda demonstra a realidade. Em outras palavras, a sustentabilidade positiva trabalha com análises científicas a respeito do desenvolvimento sustentável e da sustentabilidade, todas elas baseadas nos choques entre a economia, a ecologia e a filosofia. Embora sejam ricas em seus debates, tais análises ainda não chegaram a um acordo sobre o que deve ser feito e o que precisa ser alcançado em prol de um desenvolvimento sustentável.

A sustentabilidade normativa, por sua vez, está intensamente vinculada com uma postura conceitual institucional (MEBRATU, 1998), por se preocupar com os acordos e as propostas institucionais que envolvem a expressão desenvolvimento sustentável (OSORIO; LOBATO; CASTILLO, 2005). Independente da abordagem ser positiva ou normativa, é válido esclarecer que o conceito de sustentabilidade é uma adaptação de uma noção utilizada no domínio agrobriológico.

Nessa área, o termo é definido como a capacidade de um sistema manter sua produtividade mesmo em situações de adversidade (JIMÉNEZ HERRERO, 2000). Com o desenvolver da história, o conceito foi sendo aplicado em diversas áreas do conhecimento, o que permitiu a inclusão de aspectos referentes aos sistemas naturais por uma via ecológica e preservacionista. No estágio final de construção do conceito de sustentabilidade, o termo acabou assumindo uma perspectiva de relevância ambiental, na qual os critérios econômicos, sociais e culturais começaram a ser considerados gradativamente (JIMÉNEZ HERRERO, 2000; OSORIO; LOBATO; CASTILLO, 2005).

Percebe-se que a disseminada similaridade entre sustentabilidade e desenvolvimento sustentável não se confirma pela disparidade de suas fundamentações conceituais. Mediante esse reconhecimento, os conceitos dife- 
rem. Enquanto a sustentabilidade refere-se à capacidade de manter algo em um estado contínuo, o desenvolvimento sustentável envolve processos integrativos que buscam manter o balanço dinâmico de um sistema complexo em longo prazo. A sustentabilidade, então, pode ser considerada a ideia central do desenvolvimento sustentável, uma vez que a origem, os espaços, os períodos e os contextos de um determinado sistema se integram para um processo contínuo de desenvolvimento (JIMÉNEZ HERRERO, 2000).

Para Léle (1991), a sustentabilidade possui um significado constituído por três pilares principais: literal, ecológico e social. O significado literal referese à continuação do nada; o significado ecológico refere-se à manutenção de uma base ecológica para a vida humana, dentro de um determinado período de tempo, o que indica uma preocupação com as gerações contemporâneas e futuras; já o significado social prioriza a manutenção dos valores sociais, das instituições, das culturas e das demais características sociais (LÉLÉ, 1991).

Em relação ao desenvolvimento sustentável Lélé (1991) argumenta que duas são as possíveis interpretações: (1) crescimento sustentável (o que para ele é contraditório e trivial); e (2) realização de objetivos tradicionais, descritos como políticos e significativos. Fergus e Rowney (2005) consideram que essas interpretações concedidas por Lélé (1991) indicam que o desenvolvimento sustentável é um fenômeno consequente da estabilidade de uma série de outros fenômenos menores e interligados. Essa afirmação se justifica, pois o próprio Lélé (1991) assevera que as duas interpretações concedidas podem ser traduzidas, cada uma, em uma simples palavra: a primeira pode denunciar o desenvolvimento sustentável como um processo, uma vez que busca o crescimento; a segunda identifica o termo como um objetivo, visto que seu intuito principal está em satisfazer necessidades básicas.

Osorio, Lobato e Castillo (2005) complementam o discurso de Lélé (1991) ao considerarem que sustentabilidade e desenvolvimento sustentável se diferem quanto à busca de seus objetivos finais. A sustentabilidade representa um argumento inquestionável, pois independente de seu objetivo final, este deve ser alcançado por um equilíbrio na utilização e consumo de recursos naturais. A busca de uma sustentabilidade ambiental, por exemplo, é parte integrante de uma meta maior. O desenvolvimento sustentável se baseia na preservação dos recursos naturais, ou seja, busca os mesmos objetivos da sustentabilidade, e é complementado pela busca de um equilíbrio social, cultural e econômico (OSORIO; LOBATO; CASTILLO, 2005).

Em síntese os autores Lélé (1991), Jiménez Herrero (2000) e Osorio, Lobato e Castillo (2005) concordam que o desenvolvimento sustentável cons- 
titui a direção futura do progresso humano, por meio de processos ocorrentes em três dimensões principais: econômica, ecológica e social. Quando a economia se alia a ecologia o desenvolvimento sustentável é aceito como um objetivo e definido como um meio para o progresso humano por uma abordagem integrativa e inclusiva para as gerações contemporâneas e futuras. Quando as perspectivas ecológicas se somam as sociais, o desenvolvimento sustentável passa a ser assumido como um fenômeno processual e entendido como um discurso que integra conhecimentos, filosofias e ferramentas de mensuração altamente eficazes (LÉLÉ, 1991; FERGUS; ROWNEY, 2005).

Em relação às organizações, portanto, o desenvolvimento sustentável é tanto um objetivo quanto um processo, ou seja, representa uma meta maior constituída de metas menores a serem alcançadas em prazos específicos. Se o desenvolvimento sustentável enquanto objetivo relaciona economia e ecologia e enquanto processo interliga ecologia e sociedade, enquanto agir organizacional vincula economia, ecologia e sociedade.

A sustentabilidade compõe, assim, ações mais objetivas que propiciam o alcance de um desenvolvimento sustentável. Se considerada cada meta organizacional como um objetivo final em busca de um equilíbrio sistêmico, considera-se cada uma delas relacionadas à sustentabilidade. A soma de tais metas, ou seja, a adição de sucesso desses objetivos sustentáveis é o que permite a realização de um desenvolvimento sustentável, uma vez que a sustentabilidade busca o equilíbrio de qualquer sistema e o desenvolvimento sustentável busca a soma destes equilíbrios e mais um equilíbrio maior composto por todas as interações entre estes sistemas.

Surge então a questão: se o desenvolvimento sustentável é fenômeno maior, porque não denominar o paradigma em análise de paradigma do desenvolvimento sustentável? Como discutido anteriormente, a sustentabilidade é a ideia motriz do desenvolvimento sustentável, ou seja, por diversas sustentabilidades se realizam agires sociais que proporcionam o reconhecimento sobre a relevância de se contribuir com um tipo de desenvolvimento mais ameno com a natureza, menos prejudicial para os seres humanos e que cobre uma movimentação econômica responsável por parte das organizações. Pelo fato da sustentabilidade ser assumida, pela discussão apresentada, como o cerne do desenvolvimento sustentável, optou-se por conceder ao paradigma estudado o nome de paradigma da sustentabilidade, o qual apenas é viabilizado pela relação investigativa proporcionada pelo desenvolvimento sustentável e pelos estudos organizacionais. 
Após a contextualização das contribuições selecionadas dos estudos organizacionais, das categorizações de análise do desenvolvimento sustentável, de algumas posturas epistemológicas, da teoria do agir organizacional e da lógica das competências e da diferenciação entre sustentabilidade e desenvolvimento sustentável apresenta-se em sequencia a fundamentação do paradigma da sustentabilidade.

Por meio da tentativa de relacionar o desenvolvimento sustentável aos estudos organizacionais elaborou-se o paradigma da sustentabilidade. Por esta perspectiva paradigmática o desenvolvimento sustentável é compreendido como uma competência organizacional coletiva e abstrata. Coletiva por demandar o interesse e o comprometimento de atores sociais muitas vezes não gerenciados, mas influenciados pelas práticas organizacionais; e abstrata pela amplitude de suas consequências e pela diversidade das patologias que ressaltam a necessidade de promover o desenvolvimento sustentável como uma competência. Este nível de abstração se confirma pela capacidade do desenvolvimento sustentável ser relacionado a diferentes fatos sociais expressados por manifestações específicas de uma realidade objetiva.

Trata-se de um corpo paradigmático que admite o fenômeno em perspectiva como um agir organizacional, ou seja, como um agir social circunscrito, cujo objetivo maior é promover o equilíbrio entre as convivências sociais, econômicas e ecológicas, por atos que privilegiem a sobrevivência contemporânea e futura dos seres humanos, os quais assumem duas representações: a de seres admitidos como uma extensão natural dos sistemas sociais, ecológicos e sociais, e como os responsáveis por viabilizar os métodos que promovam o alcance de um desenvolvimento sustentável.

Esse paradigma observa a realidade por uma essência sociológica funcionalista, uma vez que concorda com o positivismo ao exigir explicações causais sobre os fenômenos sociais. Embora haja esse acordo positivista inicial, não se pode dizer que o paradigma da sustentabilidade esteja alicerçado em uma veia epistemológica advinda de uma postura ontológica fundacionalista, pois, o fato de este paradigma necessitar de explicações causais para compreender a realidade, não necessariamente denuncia que ele comunga de pressupostos objetivistas, os quais, segundo Grix (2002), informam que os fenômenos sociais e seus respectivos significados existem em um plano de independência em relação aos atores sociais que vivenciam tais fenômenos.

Para o paradigma da sustentabilidade os fenômenos sociais, bem como seus respectivos significados múltiplos, são introduzidos às comunidades, 
legitimados e, também, desprezados somente pelos atores sociais que, em conjunto, decidem a relevância de se estudar e compreender o tema (patologias, crises, disparidades sociais) que se apresenta (BRYMAN, 2001). O exemplo está no problema de maior interesse ao paradigma da sustentabilidade, a crise ambiental, que por uma abordagem construtivista é assumida como uma patologia social definida e contextualizada pelos seres humanos inseridos em diferentes comunidades, uma vez que são eles que têm o total conhecimento dos fatos sociais que o circundam (SPECTOR; KITSUSE, 1973; KLANDERMANS, 1992; TAYLOR, 2000).

As críticas sociais, nesta corrente paradigmática, são justificadas por abordagens radicais humanistas e radicais estruturalistas, por considerarem a importância da evolução histórica dos fenômenos sociais por uma lente intencionalista, em abordagens objetivas em resolução, mas subjetivas em compreensão, e que tenham o sujeito social como um agente participativo junto aos processos de decisão, assim como defende a hermenêutica filosófica.

A hermenêutica filosófica defende a concessão de poder ao indivíduo para a conquista de melhores decisões sociais, no entanto se choca com a proposição do paradigma da sustentabilidade quando este exige abordagens objetivas para resoluções e subjetivas para compreensões de problemáticas diversas. Em suma, o que o paradigma da sustentabilidade procura exercitar cientificamente é o exercício da crítica seguido de uma proposição e não somente o ato de criticar em si.

Mediante tais conjecturas é possível que o paradigma da sustentabilidade também possua uma raiz realista, uma vez que o realismo divide posições ontológicas com o positivismo e perspectivas epistemológicas com o interpretativismo. Os realistas, assim como o paradigma da sustentabilidade, tentam ir além dos positivistas, mas, também, procura não ultrapassar os limites construtivistas. Para o realismo o mundo existe e esta existência independe da capacidade humana de compreendê-la. No entanto esta distância positivista entre indivíduo e mundo é amenizada pela compreensão realista de que nem todos os fenômenos sociais podem ser diretamente observáveis por aqueles que os pesquisam. Há, portanto, uma dicotomia entre uma realidade exposta e uma realidade aparente, por meio da qual, as investigações mais aprofundadas (críticas) precisam ser realizadas com o intuito de que respostas (propostas) mais solucionadoras sejam conquistadas (HOLLIS; SMITH, 1990).

O desenvolvimento sustentável é aparente no que concerne à sua necessidade de existir e é exposto pelas calamidades que remetem à sua capa- 
cidade de remediá-las. Por mais que o paradigma da sustentabilidade agregue contribuições sobre o desenvolvimento sustentável que venham de vertentes mais rígidas e outras mais flexíveis da ciência, isso não permite categorizá-lo como realista. Em verdade, e por mais audacioso que isso possa parecer, o paradigma da sustentabilidade requer uma nova capacidade científica de observar a realidade.

Weber (1964), ao elaborar sua estrutura sociológica amplamente reconhecida em algumas de suas contribuições, evidenciou a imprescindibilidade de se construir uma nova via interpretativa para a realidade social. Em suas admoestações ele argumentava que os positivistas inflexíveis e os antipositivistas irredutíveis em suas crenças e valores deveriam ser preteridos em relação aos pesquisadores com maior capacidade de miscigenação de conhecimentos, pois por meio deles os aspectos ocultos da realidade se manifestam e se tornam, ao menos, existentes para todas as vertentes do conhecimento.

Essa proposição Weberiana foi mais bem desenvolvida por Giddens (1984), o qual nomeou essa nova maneira de interpretar a realidade como a "terceira via". A terceira via não busca posições ontológicas e perspectivas epistemológicas específicas, ao contrário, ela caminha em conformidade à natureza do fenômeno, que pode, a qualquer momento, demandar uma nova identidade compreensiva. Ela é plausível, pois descreve o que está sendo pesquisado, mas subjetiva porque para aceitar alguma informação como válida, busca diversas fontes de informações e aprecia diferentes concepções a respeito de um mesmo fato social (MAGGI, 2003a).

Em suma, o paradigma da sustentabilidade, discorre a respeito do desenvolvimento sustentável enquanto fenômeno de interesse às ciências organizacionais, logo, representa um interesse organizacional simultaneamente compreendido como um objetivo e como uma sistemática processual. O desenvolvimento sustentável é um ato de gestão (agir) organizacional, ou seja, requer uma estrutura de 'agires' sobre os quais as organizações, em seus relacionamentos internos e externos e em suas operações diversas realizam atividades que, junto à realidade e ao contexto do qual participam, propiciam o exercício de se aproximar de um desenvolvimento sustentável.

Em síntese, o desenvolvimento sustentável como fenômeno de análise para diferentes contextos organizacionais, é tanto um agir coletivo quanto um agir abstrato, e, muito mais, um construto em evolução, uma vez que depende de interferências que são e não são controláveis pelas organizações. A Figura 1 expõe a constituição desse paradigma. 


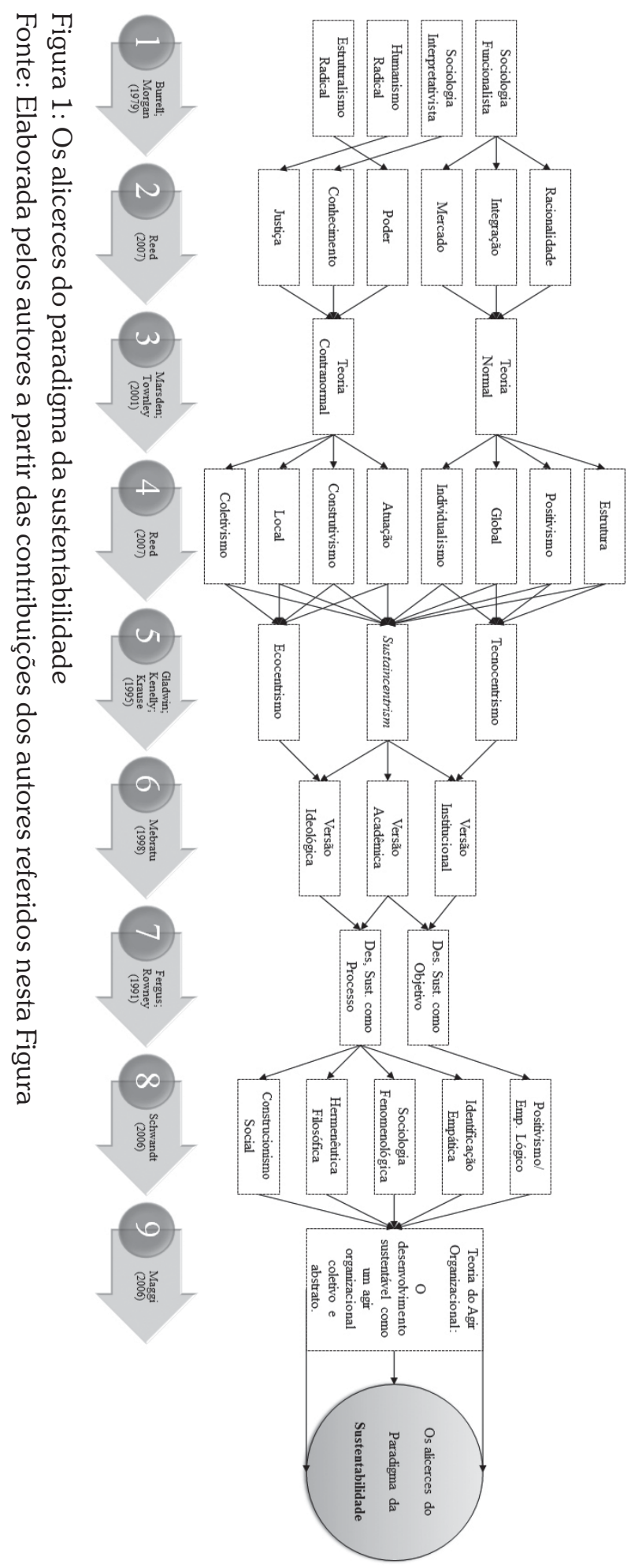


Pela descrição do paradigma e pela exposição de seus alicerces paradigmáticos cumprem-se com os dois objetivos principais deste artigo, uma vez que foi introduzido o paradigma da sustentabilidade como ente condicionado pelo ecletismo dos estudos organizacionais. Ele representa um exercício científico de encontro e confronto de diferentes abordagens do conhecimento. Tal esforço dialógico pode ser aceito por alguns cientistas organizacionais como uma proposição construtiva e para outros entendidos como uma tentativa de racionalizar a realidade. Independente das interpretações que tal proposição venha a angariar vale a ressalva de que o que mais se deseja é que este paradigma seja não somente aceito ou rejeitado, mas também confrontado com outras contribuições, enriquecido por outras pesquisas e, até mesmo, validado por considerações de estudos nacionais e internacionais.

Os alicerces deste paradigma compõem uma extensa agenda de pesquisa a respeito de quais relações evidenciadas na Figura 1 podem ser compreendidas como críticas, ou seja, como imprescindíveis para a contextualização teórica e aplicação empírica do paradigma da sustentabilidade.

\section{Considerações Finais}

Este artigo foi desenvolvido com o intuito de oferecer resposta para os seguintes objetivos: (1) apresentar e definir um paradigma da sustentabilidade, por meio do qual o desenvolvimento sustentável pudesse ser assumido como um fenômeno de pesquisa coerente junto aos estudos organizacionais; e (2) demonstrar que esse paradigma, como proposição de lente de observação da realidade para os contextos organizacionais, deve assumir uma postura eclética, dialógica e flexível.

Ao longo do texto foram expostas considerações por meio das quais cada um dos objetivos supramencionados foram respondidos. Esclarece-se, no entanto, que as respostas conferidas não estão fechadas em si ou concluídas no escopo deste estudo. Acredita-se, e isso é o que mais instiga a investigação de um paradigma da sustentabilidade, que muitas das discussões a respeito do mesmo ainda não podem ser consideradas como completas, uma vez que o fenômeno pesquisado por ele, o desenvolvimento sustentável, é mutante e eclético. 
Assim como Popper (1985) identificou em suas arguições, cada tema possui seus contextos específicos, os quais, pelas palavras do autor podem ser segmentados em um contexto de descoberta e um contexto de justificação. O primeiro exige a precisão e o detalhamento do que circunda o fenômeno pesquisado enquanto que o segundo busca uma legitimação social para a necessidade de se continuar pesquisando este mesmo fenômeno (POPPER, 1985). O desenvolvimento sustentável, em tentativas de aproximação dos estudos organizacionais, busca, simultaneamente, ser descoberto pelas organizações e ser aceito como relevante por elas.

Essa miscelânea contextual remete aos diferentes tipos de sociedades nas quais o desenvolvimento sustentável é discutido, sendo que, em cada uma delas, as organizações exercem seus poderes de influência. Nessas comunidades, umas maiores do que as outras, a linguagem pode ser utilizada como instrumento formal de expressão do pensamento, ou ainda, como pragmática, uma vez que buscará legitimação social para o discurso que se tenta proclamar (OLIVEIRA, 1996).

Essa evolução linguística, muito estudada por Kant (1966), expressa uma relativização da lógica que explica e conduz a explicação do fenômeno pesquisado. Esse caráter multilinguístico é característica inerente ao paradigma da sustentabilidade, uma vez que ele demanda o conhecimento de muitas vozes. Ressalta-se, porém que ao compreender esta relativização dos conceitos do que se estuda este paradigma não concede margem para uma adesão a um anarquismo epistemológico, o qual, de acordo com Mattos (2010), busca uma problematização que perpassa os caminhos dicotômicos entre o queé objetivo e o que é subjetivo, sem que caminhos mais completos, que orientem para um entendimento da realidade, sejam apresentados.

Em face de toda a discussão estabelecida é possível conceber que as abordagens organizacionais contribuem para que o desenvolvimento sustentável seja analisado pelas mesmas como um fenômeno de investigação desde que permissivas de uma integração paradigmática, epistemológica e teórica possibilitadas pelo paradigma da sustentabilidade. Esse paradigma foi apresentado após a respectiva introdução e menção de seus alicerces junto a proposições oriundas das ciências organizacionais e de estudos diretamente relacionados ao desenvolvimento sustentável.

Pela diversidade epistemológica, conceitual e paradigmática destes alicerces nota-se a evidência de seu ecletismo quando relacionado a pesquisas que importam aos contextos organizacionais. Essas foram as intenções prin- 
cipais deste artigo. A escolha de apenas uma teoria organizacional para viabilizar o relacionamento entre o desenvolvimento sustentável e os estudos organizacionais foi explicada no decorrer do artigo. Mas, vale ressaltar que a teoria do agir organizacional possui uma essência interdisciplinar, assim como o termo desenvolvimento sustentável e o paradigma da sustentabilidade.

Essa teoria finalizou as discussões de maneira singela por constarem em suas estruturas fatos e contribuições que remetem aos paradigmas de Burrell e Morgan (1979), aos pontos de interseção de Reed (2007), a segmentação teórica proposta por Marsden e Townley (2001) e as posturas epistemológicas abordadas por Schwandt (2006). Essa teoria viabiliza a relação de todas essas abordagens organizacionais aos requisitos estabelecidos pelas categorizações de Gladwin, Kennelly e Krause (1995), Mebratu (1998), Fergus e Rowney (2005) e Lélé (1991). Por suportar tal fundamentação eclética, a teoria do agir organizacional representou o alicerce último, mas não menos importante do paradigma da sustentabilidade, uma vez que por ela se confirmou o caráter eclético, dialógico e pluralista desse corpo paradigmático.

As discussões aqui abordadas são passíveis de críticas e debate, logo não são aceitas como uma verdade absoluta e inquestionável. Os autores deste artigo se propõem a lançar esse debate ao compreenderem a urgência das ciências organizacionais assumirem sua representatividade teórica e empírica junto a esforços que tentem relacionar práticas de gestão e rotinas organizacionais a ações que promovam e evidenciem o alcance de um desenvolvimento sustentável.

\section{The Ecletism of the Paradigm of Sustainability: framing and analysis from organizational studies}

\section{Abstract}

This article has two mainly objectives: (1) to investigate the perspectives that the paradigm of sustainability, as a lens of reality observation, must assume; and, (2) to present and to define an eclectic, dialogical and flexible paradigm of sustainability, for which the sustainable development can be accepted as a coherent 
research phenomena to the organizational studies. It was realized a bibliographical, exploratory and qualitative research. It was developed a theoretical study about specific contributions related to the organizational studies and to the sustainable development. The paradigm of the sustainability is generated through the study of the relation between the sustainable development and the organizational studies, once that, for this paradigm the sustainable development is an investigation phenomena that is interesting to the organizational contexts.

Key words: Sustainable Development. Organizational Studies. Paradigm.

\section{Referências}

ASTLEY, W. G. Administrative science as socially constructed truth. Administrative Science Quarterly, v. 30, p. 497-513, 1985.

BERTERO, C. O. Nota técnica: a coruja de minerva: reflexões sobre a teoria na prática. In: CLEGG, S.; HARDY, C.; NORD, W. R. (Org.) Handbook de estudos organizacionais: reflexões e novas direções. São Paulo: Atlas, 2001. p. $57-60$.

BRYMAN, A. Social research methods. Oxford: Oxford University Press, 2001.

BURRELL, G. Ciência normal, paradigmas, metáforas, discursos e genealogia da análise. In: CLEGG, S. R; HARDY, C.; NORD, W. R. (Org.) Handbook de estudos organizacionais: modelos de análise e novas questões em estudos organizacionais. São Paulo: Atlas, 2007. p. 437-460.

BURRELL, G.; MORGAN, G. Social paradigms and organisational analysis: elements of the sociology of corporate life. Great Britain: Heinemann Education Books, 1979.

CLARK, W. C. Managing planet earth. Scientific American, v. 261, n. 3, p. 47-54, 1989.

DENZIN, N. K.; LINCOLN, Y. S. Introdução: a disciplina e a prática da pesquisa qualitativa. In: O planejamento da pesquisa qualitativa: teorias e abordagens. Porto Alegre: Artmed, 2006. p. 15-42.

FERGUS, A. H. T.; ROWNEY, J. I. A. Sustainable development: lost meaning and opportunity? Journal of Business Ethics, v. 60, p. 17-27, 2005. 
FLICK, U. Introdução à pesquisa qualitativa. 3. ed. Porto Alegre: Artmed, 2009.

GARCIA, J. R.; MINUZZI; J. As tarefas sob a luz das metáforas das organizações de Morgan. In: SIMPÓSIO DE ENGENHARIA DE PRODUÇÃO, 2005, Bauru. Anais... Bauru: XII SIMPEP, p. 10, 2005.

GIDDENS, A. The constitution of society. Cambridge: Polity Press, 1984.

GIL, A. C. Métodos e técnicas de pesquisa social. 6. ed. São Paulo: Atlas, 2008.

GLADWIN, T. N.; KENNELLY, J. J.; KRAUSE, T. S. Shifting paradigms for sustainable development: implications for management theory and research. Academy of Management, v. 20, n. 4, p. 874-907, 1995.

GORE, A. Earth in balance: ecology and the human spirit. New York: Houghton Miffin, 1992.

GRIX, J. Introducing students to the generic terminology of social research. Politics, v. 22, n. 3, p. 175-186, 2002.

HOLLIS, M.; SMITH, S. Explaining and understanding international relations. Oxford: Clarendon Press, 1990.

JIMÉNEZ HERRERO, L. M. Desarrollo Sostenible: transición hacia la coevolución global. Madrid: Pirámide Ediciones, 2000.

KANT, E. Crítica da razão pura. Rio de Janeiro: Edições de Ouro, 1966.

KLANDERMANS, B. The social construction of protest and multiorganization fields. In: MORRIS, A. D.; MUELLER. C. M. (Org.) Frontiers in social movement theory. New Haven: Yale University Press, 1992. p. 77-103.

KUHN, T. The structure of scientific revolutions. 2. ed. Chicago: University of Chicago Press, 1970.

LAUDAN, L. Beyond positivism and relativism: theory, method and evidence. Oxford: Westview Press, 1996.

LEE, K. N. Greed, scale mismatch and learning. Ecological Applications, v. 3, n. 4, p. 560-564, 1993. 
LEFF, E. Saber ambiental: sustentabilidade, racionalidade, complexidade, poder. 6. ed. Petrópolis: Vozes, 2008.

LÉLÉ, S. M. Sustainable development: a critical review. World Development, v. 19, n. 6, p. 607-621, 1991.

LINCOLN, Y. S.; GUBA, E. G. Controvérsias paradigmáticas, contradições e confluências emergentes. In: DENZIN, N. K.; LINCOLN, Y. S. (Org.). O planejamento da pesquisa qualitativa: teorias e abordagens. Porto Alegre: Artmed, 2006. p. 169-192.

MAGGI, B. Razionalità e benessere: studio interdisciplinare dell'organizzazione. Milano: Etas Libri, 1984.

MAGGI, B. Maniéres de penser, maniéres d'agir en éducation et en formation. Paris: PUF, 2000.

MAGGI, B. Le competenze per il cambiamento organizativo: casi e dibatti dell'Officina di Organizazzione. Milano: Etas, 2001.

MAGGI, B. De l'agir organisationnel: un point de vue sur le travail, le bien être, l'apprentissage. Toulouse : Octarès Editions, 2003a.

MAGGI, B. Régulation sociale et action organizationnelle: théories en perspective. In: TERSSAC, G. de (Ed.). La théorie de la régulation sociale de Jean-Daniel Reynaud: debats et prolongements. Paris: La DéCouverte, 2003b. v. 1, Chap. 6, p. 287-315

MARSDEN, R.; TOWNLEY, B. Introdução: a coruja de minerva: reflexões sobre a teoria na prática. In: CLEGG, S.; HARDY, C.; NORD, W. R. (Org.) Handbook de estudos organizacionais: reflexões e novas direções. São Paulo: Atlas, 2001. p. 31-56.

MARTINS, G. A.; THEÓPHILO, C. R. Metodologia da investigação científica para ciências sociais aplicadas. São Paulo: Atlas, 2007.

MATTOS, P. L. C. L. Administração é Ciência ou Arte? O que podemos aprender com este mal-entendido? RAE - Revista de Administração de Empresas, v. 49, n. 3, p. 349-360, jul./set., 2009. 
MATTOS, P. L. C. L. Relações Teoria-Prática em Administração: o que Desaparece nesse Buraco Negro. In: ENCONTRO DA ASSOCIAÇÃO NACIONAL DE PÓS-GRADUAÇÃO EM ADMINISTRAÇÃO, 34., Rio de Janeiro. Anais... Rio de Janeiro: ENANPAD, 2010.

MEBRATU, D. Sustainability and sustainable development: historical and conceptual review. Environment Impact Assessment Review, v. 18, p. 493520, 1998.

MILNE, M. J.; KEARINS, K.; WALTON, S. Creating adventures in wonderland: the journey metaphor and environmental sustainability. Organization, v. 13, n. 6, p. 801-839, 2006.

MORGAN, G. Paradigms, metaphors, and puzzle solving in organization theory. Administrative Science Quarterly, v. 25, p. 605-622, 1980.

OLIVEIRA, M. A. Reviravolta linguístico-pragmática na filosofia contemporânea. São Paulo: Loyola, 1996.

OSORIO, L. A. R.; LOBATO, M. O.; CASTILlO, X. A. Debates on sustainable development: towards a holistic view of reality. Environment, Development and Sustainability, v. 7, p. 501-518, 2005.

POPPER, K. Conjectures and refutations: the growth of scientific knowledge. 4. ed. London: Routledge\&Kegan Paul, 1985.

REDCLIFT, M.; BENTON, T. Social theory and the global environment. London: Routledge, 1994.

REED, M. Teorização organizacional: um campo historicamente contestado. In: CLEGG, S. R; HARDY, C.; NORD, W. R. (Org.) Handbook de estudos organizacionais: modelos de análise e novas questões em estudos organizacionais. São Paulo: Atlas, 2007, p. 61-97.

RICHARDSON, R. J. et al. Pesquisa social: métodos e técnicas. 3. ed. São Paulo: Atlas, 2008.

ROLSTON, H. Conserving natural value. New York: Columbia University Press, 1994. 
ROTHSCHILD, E. Sentimentos econômicos: Adam Smith, Condorcet e o iluminismo. Rio de Janeiro: Record, 2003.

SCHWANDT, T. A. Três posturas epistemológicas para a investigação qualitativa. Interpretativismo, hermenêtica e construcionismo social. In: DENZIN, N. K.; LINCOLN, Y. S. (Org.) O planejamento da pesquisa qualitativa: teorias e abordagens. Porto Alegre: Artmed, 2006. p.193-218.

SPECTOR, M.; KITSUSE, J. Social problems: a reformulation. Social Problems, v. 20, p. 145-159, 1973.

TAYLOR, D. E. The rise of the environmental justice paradigm: injustice framing and the social construction of the environment discourses. American Behavioral Scientist, v. 43, n. 4, p. 508-580, 2000.

TRYZNA, T. C. A sustainable world. Sacramento: IUCN, 1995.

VIEDERMAN, S. The economics of sustainability: challenges. Recife: Fundação Joaquim Nabuco, 1994. Paper presented at the workshop. The Economics of Sustainability.

WEBER, M. The theory of social and economic organization. New York: The Free Press, 1964.

WCED - World Comission on Environment and Development. Our common future (the Brundtland report). Oxford: Oxford University Press, 1987. 